\title{
QUALIDADE DE FRUTOS DE MELANCIA SEM SEMENTES EM FUNÇÃO DE FONTES E DOSES DE POTÁSSIO
}

\author{
Quality of seedless watermelon fruits as a function of sources and doses of potassium
}

\author{
Arthur Bernardes Cecílio Filho ${ }^{1}$, Leilson Costa Grangeiro ${ }^{1}$
}

\begin{abstract}
RESUMO
O experimento foi conduzido em propriedade rural próxima à cidade de Borborema - SP, no período de fevereiro a abril de 2002, com o objetivo de avaliar a qualidade de frutos de melancia sem sementes (Citrullus lanatus (Thumb.) Matsum. \& Nakai), híbrido Shadow, em função de fontes e doses de potássio. O delineamento experimental utilizado foi o de blocos casualizados completos, em esquema fatorial $3 \times 4$, com três repetições, sendo utilizadas as fontes: cloreto, nitrato e sulfato de potássio e as doses: 50; 100; 200 e $300 \mathrm{~kg} \mathrm{ha}^{-1}$ de $\mathrm{K}_{2} \mathrm{O}$. Foram avaliados: sólidos solúveis totais (SST), acidez total titulável (ATT), relação SST/ATT e espessura da casca. O teor de sólidos solúveis aumentou à medida que se aumentou a dose de potássio, enquanto a relação SST/ATT reduziu. A acidez titulável não foi influenciada pelos fatores estudados. A maior espessura da casca foi obtida ao se utilizar a dose de $202 \mathrm{~kg} \mathrm{ha}^{-1} \mathrm{de}_{2} \mathrm{O}$ na forma de $\mathrm{KNO}_{3}$, seguida pela dose de $300 \mathrm{~kg} \mathrm{ha}^{-1}$ de $\mathrm{K}_{2} \mathrm{O}$, na forma de $\mathrm{KCl}$.
\end{abstract}

Termos para indexação: Citrullus lanatus, nutrição de plantas, fertilizantes potássicos.

\section{ABSTRACT}

The experiment was carried out in the Borborema region, State of São Paulo, in the period of February the April to 2002, with the objective to evaluate the quality of seedless watermelon fruits (Citrullus lanatus (Thumb.) Matsum. \& Nakai) as a function of sources and doses of potassium. The experimental design was a randomized complete block, with three replications, in $3 \times 4$ factorial scheme, being evaluated sources: potassium chloride, nitrate and sulphate and doses 50, 100, $200 \mathrm{and} 300 \mathrm{~kg}$ $\mathrm{ha}^{-1} \mathrm{~K}_{2} \mathrm{O}$. Total soluble solids (TSS), total titrable acidity (TTA), ratio TSS/TTA and rind thickness were evaluated. Soluble solids increased and ratio TSS/TTA decreased with increment of K dose. Sources and doses of potassium did not affect total titrable acidity. The biggest rind thickness was achieved with 202 and $300 \mathrm{~kg} \mathrm{ha}^{-1} \mathrm{~K}_{2} \mathrm{O}$ of $\mathrm{KNO}_{3}$ and $\mathrm{KCl}_{\text {, }}$ respectively.

Index terms: Citrullus lanatus, plant nutrition, potassium fertilizers.

(Recebido para publicação em 1 de novembro de 2003 e aprovado em 29 de dezembro de 2003)

\section{INTRODUÇÃO}

No Brasil, a produção de melancia sem sementes (Citrullus lanatus (Thumb.) Matsum. \& Nakai) é ainda incipiente, embora algumas pequenas áreas comerciais já tenham sido implantadas nas diferentes regiões produtoras. O menor tamanho do fruto, característica que facilita o transporte e acondicionamento, bem como a ausência de sementes, explorada comercialmente pelas empresas como novidade de mercado, são os principais aspectos que contribuem para a expansão de seu cultivo. Nos Estados Unidos, até 1991, a melancia sem sementes ocupava cerca de $5 \%$ do mercado, com estimativa de ter potencial para ocupar de $15 \%$ a $50 \%$ (MARR e GAST, 1991). Atualmente, estima-se que o mercado da melancia sem sementes naquele país seja de $20 \%$. Um dos empecilhos ao crescimento da área cultivada tem sido a escassez de informações técnicas, sobretudo relativas à nutrição e adubação da cultura, o que pode afetar diretamente a qualidade dos frutos.

A importância crucial do potássio na formação da qualidade baseia-se na sua função de promotor da síntese de fotossintatos e seu transporte para frutos, grãos, tubérculos e órgãos de armazenamento da planta, aumentando a conversão daqueles em amido, proteína, vitaminas, óleos, etc. (MENGEL e KIRKBY, 1987). Em muitas hortaliças, o potássio tem importância fundamental nos parâmetros de qualidade. Na batata, Reis Júnior (1995) verificou que a adubação potássica aumentou o conteúdo de água dos tubérculos, gravidade específica e os teores de massa seca e amido. Quando as doses foram excessivas, Westermann et al. (1994) observaram reduções nos teores de amido e massa seca, sendo essas reduções ocasionadas pelo aumento do teor de água dos tubérculos, fato esse indesejável, principalmente se a batata for utilizada para fritura. Em bata- 
ta-doce, muitos parâmetros qualitativos da raiz foram incrementados com a nutrição potássica, tais como massa seca, brix, teor de caroteno e antocianina (GEORGE et al., 2002).

Em tomateiro, o potássio incrementou o sabor e maturação (HARTZ et al., 1999), acidez (FONTES et al., 2000), firmeza do fruto (MONTOYA et al., 2002), teor de vitamina $\mathrm{C}$ e massa seca (WUZHONG, 2002). Também reduziu a incidência de algumas desordens fisiológicas ocorridas durante o amadurecimento do fruto, que se caracterizam por uma coloração anormal dos tecidos do pericarpo "blotchy ripening"- amadurecimento manchado (KINET e PEET, 1997). No meloeiro, o potássio proporcionou maior peso e comprimento de fruto (KANO, 2002), acréscimo significativo de 62\% na resistência da polpa (FERNANDES, 2002) e aumento no teor de açúcar (AYDIN et al., 2002). Na melancia, a espessura e resistência da casca (SUNDSTROM e CARTER, 1983; DESWAL e PATIL, 1984) e sólidos solúveis (EL-BEHEIDI et al., 1990) aumentaram com a adubação potássica.

O cloreto de potássio tem sido a fonte de potássio mais utilizada na produção de hortaliças, principalmente por seu baixo custo. Em algumas oleráceas, têm sido verificados problemas com excesso de cloro, afetando, na maioria das vezes, a qualidade do produto colhido. Nesse sentido, Panique et al. (1997), num estudo comparativo de fontes de potássio, verificaram que o cloreto de potássio diminuiu o conteúdo de amido e o peso específico de tubérculos de batata, aumentou o teor de água dos tubérculos de batata e reduziu o período de armazenamento e a qualidade dos mesmos para fritura (ZEHLER et al., 1986). Os mesmos autores observaram que em espinafre as plantas adubadas com $\mathrm{K}_{2} \mathrm{SO}_{4}$ conservaram melhor a sua qualidade, pois, após quatro dias de armazenamento, apresentaram perda de umidade de $19 \%$, enquanto as adubadas com $\mathrm{KCl}$ tiveram perdas de $24 \%$. Embora o $\mathrm{KCl}$ seja bastante empregado na cultura da melancia, não são comuns na literatura trabalhos nos quais se verifica a influência comparativa de fertilizantes potássicos na qualidade de frutos de melancia.

Nesse contexto, com o presente trabalho tevese como objetivo avaliar a qualidade de frutos de melancia sem sementes, em função de fontes e doses de potássio.

\section{MATERIAL E MÉTODOS}

O experimento foi conduzido em uma propriedade rural localizada próxima à cidade de Borborema - SP, no período de fevereiro a abril de 2002, em solo classificado como Argissolo Vermelho-Amarelo distrófico textura média (EMBRAPA, 1999). Da área experimental, foram retiradas amostras, cujas análises químicas revelaram os seguintes resultados: $\mathrm{pH}(\mathrm{Ca}-$ $\mathrm{Cl}_{2}$ ) $=4,8 ; \mathrm{P}$ (resina) $=3 \mathrm{mg} \mathrm{dm}^{-3} ; \mathrm{S}=5 \mathrm{mg} \mathrm{dm}^{-3}$; M.O. $=11 \mathrm{~g} \mathrm{dm}^{-3} ; \mathrm{K}=1,0 \quad \mathrm{mmol}_{\mathrm{c}} \mathrm{dm}^{-3} ; \mathrm{Ca}=9$ $\mathrm{mmol}_{\mathrm{c}} \mathrm{dm}^{-3} ; \mathrm{Mg}=5 \mathrm{mmol}_{\mathrm{c}} \mathrm{dm}^{-3} ; \mathrm{SB}=15 \mathrm{mmol}_{\mathrm{c}} \mathrm{dm}^{-3}$; $\mathrm{T}=31$ e $\mathrm{V}=48 \%$. O delineamento experimental utilizado foi o de blocos casualizados completos, em esquema fatorial $3 \times 4$, com três repetições, sendo utilizadas as fontes cloreto, nitrato e sulfato de potássio e as doses 50; 100; 200 e $300 \mathrm{~kg}$ de $\mathrm{K}_{2} \mathrm{O} \mathrm{ha}^{-1}$. Cada parcela foi composta de três linhas com 8 plantas cada uma, do híbrido sem sementes Shadow, espaçadas de 3,0 m entre linhas e 1,0 m entre plantas. Utilizou-se a linha central como área útil da parcela, excluindo-se a primeira e última planta da linha. Entre as parcelas foi plantada uma linha do híbrido de melancia com semente Tide, no espaçamento de 3,0 m x 1,7 m como polinizador.

Após aração e gradagem, fez-se a distribuição do calcário dolomítico em área total, incorporando-o com grade, 50 dias antes do transplantio, em quantidade para elevar a saturação por bases a 70\% (RAIJ et al., 1997). Após esse período, procedeu-se à abertura dos sulcos com aproximadamente $30 \mathrm{~cm}$ de profundidade e realizou-se a adubação.

$\mathrm{O} \mathrm{N}$ foi aplicado na forma de nitrato de amônio em doses equivalentes a $30 \mathrm{~kg} \mathrm{~N}^{-1}$ no sulco e $90 \mathrm{~kg} \mathrm{~N} \mathrm{ha}^{-1}$ parcelado em três vezes. Para as doses de $50 ; 100 ; 200$ e $300 \mathrm{~kg} \mathrm{~K}_{2} \mathrm{O} \mathrm{ha}{ }^{-1}$ fornecidas por meio de nitrato de potássio, foram necessários 26,3; 22,6; 15,2 e 7,8 kg N ha ${ }^{-1}$ na forma de nitrato de amônio para complementar a dose de $30 \mathrm{~kg} \mathrm{~N}^{-1}$ prevista para o plantio e em cada uma das três coberturas.

No sulco, foram aplicados também $240 \mathrm{~kg} \mathrm{ha}^{-1}$ de $\mathrm{P}_{2} \mathrm{O}_{5}$ nas formas de superfosfato simples e de superfosfato triplo, para fornecer $50 \mathrm{~kg} \mathrm{ha}^{-1}$ de enxofre. Os tratamentos com dose de 200 e $300 \mathrm{~kg} \mathrm{~K}_{2} \mathrm{O} \mathrm{ha}^{-1}$ na fonte de $\mathrm{K}_{2} \mathrm{SO}_{4}$ receberam 67 e $100 \mathrm{~kg} \mathrm{~S} \mathrm{ha}^{-1}$. 
As doses de $\mathrm{K}$ foram parceladas em $25 \%$ no sulco, $25 \%$ aos 7 dias após o transplantio (DAT), $25 \%$ aos 21 DAT e $25 \%$ aos 35 DAT, juntamente com o nitrogênio.

A semeadura foi realizada em bandejas de poliestireno expandido para 128 mudas, preenchidas com substrato comercial, onde permaneceram em casa-devegetação por um período de 30 dias até o transplante. A partir dos 20 DAT, foram feitas adubações foliares semanalmente, junto com os defensivos, empregando 200 $\mathrm{mL}$ por $100 \mathrm{~L}$ de solução dos produtos contendo: $0,6 \mathrm{~g}$ $\mathrm{L}^{-1}$ de $\mathrm{Mg}$; 0,8 $\mathrm{g} \mathrm{L}^{-1}$ de Ca e 0,05 $\mathrm{g} \mathrm{L}^{-1}$ de B; 0,3 $\mathrm{g} \mathrm{L}^{-1}$ de $\mathrm{Zn} ; 0,2 \mathrm{~g} \mathrm{~L}^{-1}$ de $\mathrm{Mn}$ e $0,01 \mathrm{~g} \mathrm{~L}^{-1}$ de Mo. A quantidade de chuvas, no período, foi de $253 \mathrm{~mm}$ e não tendo sido realizada irrigação complementar, pois não existia fonte de captação de água na área experimental.

Além das pulverizações com defensivos agrícolas, foram realizadas capinas e penteamento das ramas. A colheita dos frutos foi iniciada aos 65 DAT, sendo realizadas duas colheitas com intervalo de sete dias.

Para avaliação, foram selecionados dois frutos representativos de cada parcela. Foram medidos: sólidos solúveis totais, por refratometria ( $\left.{ }^{\circ} \mathrm{Brix}\right)$; acidez total titulável, por meio da titulação com solução $\mathrm{NaOH}(0,1$ $\mathrm{N}$ ) previamente padronizada (g ácido cítrico $/ 100 \mathrm{~mL}$ de suco); relação entre sólidos solúveis e acidez total; espessura da casca (casca + polpa branca), determinada com emprego de régua graduada na região mediana do fruto (mm).

A análise de variância das características avaliadas foram realizadas pelo software ESTAT, da FCAV UNESP. Conforme Gomes (1990), para o fator quantitativo (doses), foi feita análise de regressão, ao passo que para o fator qualitativo (fontes), foi utilizado o teste $\mathrm{Tu}$ key ao nível de $5 \%$ de probabilidade

\section{RESULTADOS E DISCUSSÃO}

Verificou-se efeito significativo das doses de potássio para as características sólidos solúveis totais e a relação sólidos solúveis e acidez. Para espessura da casca, foi significativa a interação fontes e doses de potássio. A acidez total não foi influenciada por nenhum fator.

Os teores de sólidos solúveis totais responderam significativamente ao incremento da adubação potássi- ca, atingindo valor máximo de $12,3^{\circ}$ Brix com aplicação de $140 \mathrm{~kg} \mathrm{~K}_{2} \mathrm{O} \mathrm{ha}{ }^{-1}$, reduzindo a partir de então, atingindo o menor teor de sólidos solúveis $\left(11,7^{\circ} \mathrm{Brix}\right)$ na dose máxima de $\mathrm{K}_{2} \mathrm{O}$ utilizada (Figura 1). Deswal e Patil (1984) também verificaram aumentos dos teores de sólidos solúveis em melancia com aplicação de potássio. O aumento do teor de sólidos solúveis dos frutos, em função da adubação potássica, deve-se ao papel importante que esse nutriente desempenha na translocação de fotossintatos e na ativação de diversas enzimas, como foi também verificado em tomate (HARTZ et al., 1999), melão (AYDIN, 2002) e pimentão (NANNETTI, 2001). Os teores de sólidos solúveis totais obtidos no presente trabalho foram superiores aos encontrados por Souza et al. (1999) e Morales e Simon (2002), em cultivares de melancia sem sementes. Essa diferença pode ser atribuída às cultivares, ao local de plantio e ao sistema de produção.

A acidez total titulável não respondeu significativamente às doses e fontes de potássio. A média da acidez total foi de 0,247 g ácido cítrico/100 ml de suco. A relação sólidos solúveis/acidez titulável foi reduzida à medida que se aumentaram as doses de potássio, e a maior relação $(52,1)$ foi obtida na dose de $50 \mathrm{~kg} \mathrm{~K} \mathrm{~K}_{2} \mathrm{O}$ $\mathrm{ha}^{-1}$ (Figura 1). Em tomateiro, Montoya et al. (2002) também verificaram redução nessa relação em função do aumento da concentração de potássio na solução nutritiva.

A relação sólidos solúveis/acidez titulável é uma das melhores formas de avaliação do sabor, sendo mais representativa que a medição isolada de açúcares ou da acidez, proporcionando boa idéia do equilíbrio entre esses dois componentes (CHITARRA e CHITARRA, 1990). Em algumas culturas, já foi determinada a relação que proporciona melhor sabor do fruto. Em tomate, o fruto é considerado de excelente qualidade quando apresenta relação 10:1 (REINA, 1990). Em melão, o fruto pode ser considerado adequado para o consumo quando a relação é superior a 25:1 e quando a acidez é igual ou inferior a 0,5\% (CRUESS, 1973). Na melancia, Garcia (1998) obteve relações que variam de 26,7 a 30:1, valores esses muito inferiores aos observados neste trabalho. Entretanto, deve-se tomar cuidado em situações em que a acidez e o teor de sólidos solúveis são baixos, pois podem proporcionar relação SST/ATT elevada, induzindo a interpretações errôneas com relação ao sabor do fruto. 
O desdobramento da interação doses dentro de cada fonte de potássio para a característica espessura da casca do fruto revelou efeito significativo para as fontes $\mathrm{KCl}$ e $\mathrm{KNO}_{3}$. Com $\mathrm{KCl}$, o comportamento foi linear, atingindo $12,4 \mathrm{~mm}$ na dose de $300 \mathrm{~kg} \mathrm{~K}_{2} \mathrm{O} \mathrm{ha}^{-1}$, ao passo que, no $\mathrm{KNO}_{3}$, o comportamento foi quadrático, com máximo de 12,7 $\mathrm{mm}$, atingido na dose de $202 \mathrm{~kg} \mathrm{~K}_{2} \mathrm{O}$ ha $^{-1}$ (Figura 2). Comportamento semelhante foi verificado por
Sundstrom e Carter (1983), quando obtiveram aumentos de $10 \%$ na espessura e de $6 \%$ na resistência da casca de frutos de melancia, conseguidos com o aumento da dose de potássio de 0 para $209 \mathrm{~kg} \mathrm{ha}^{-1}$. Em abacaxizeiro, o potássio não influenciou a espessura da casca do fruto, mas melhorou a firmeza (PAULA et al., 1985), fato esse também verificado em frutos de tomate (LOCASCIO et al., 1990).

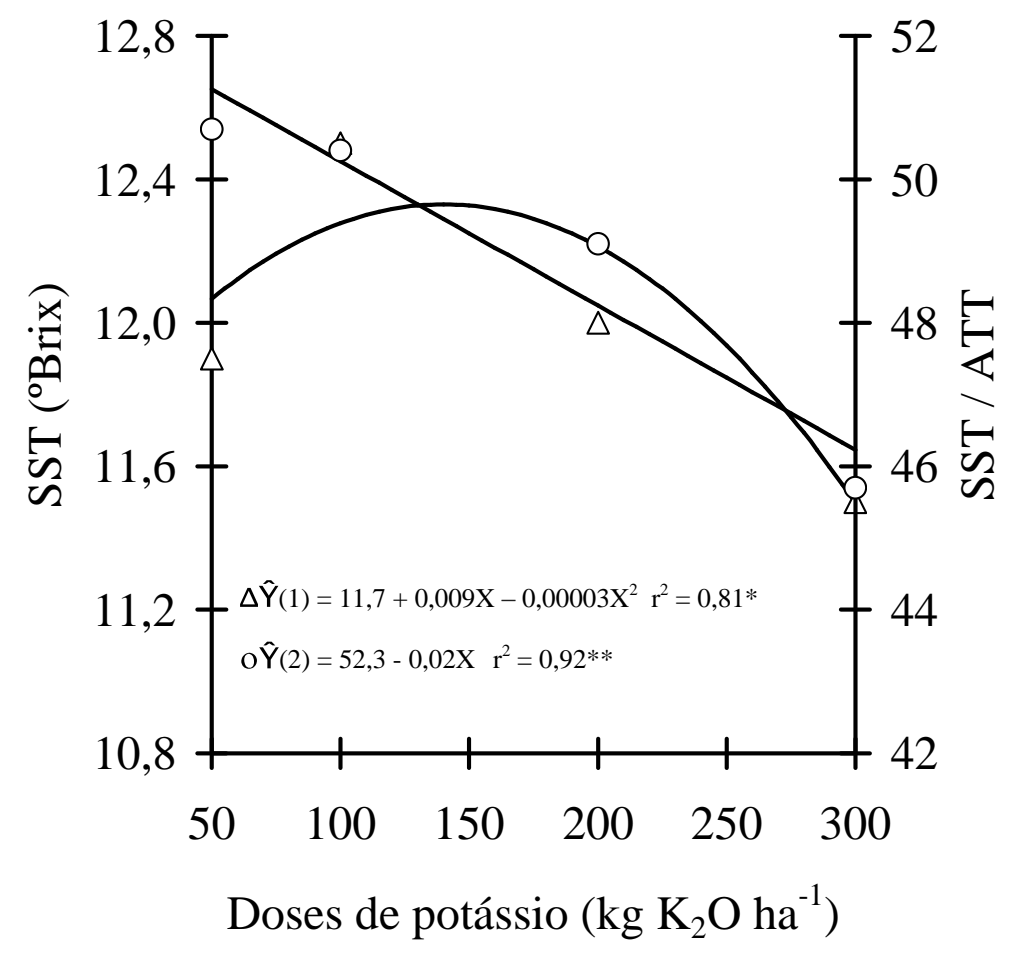

FIGURA 1 - Sólidos solúveis (Y1) e relação SST/ATT (Y2) de frutos de melancia sem sementes, híbrido Shadow, em função de dose de potássio. Borborema - SP. 


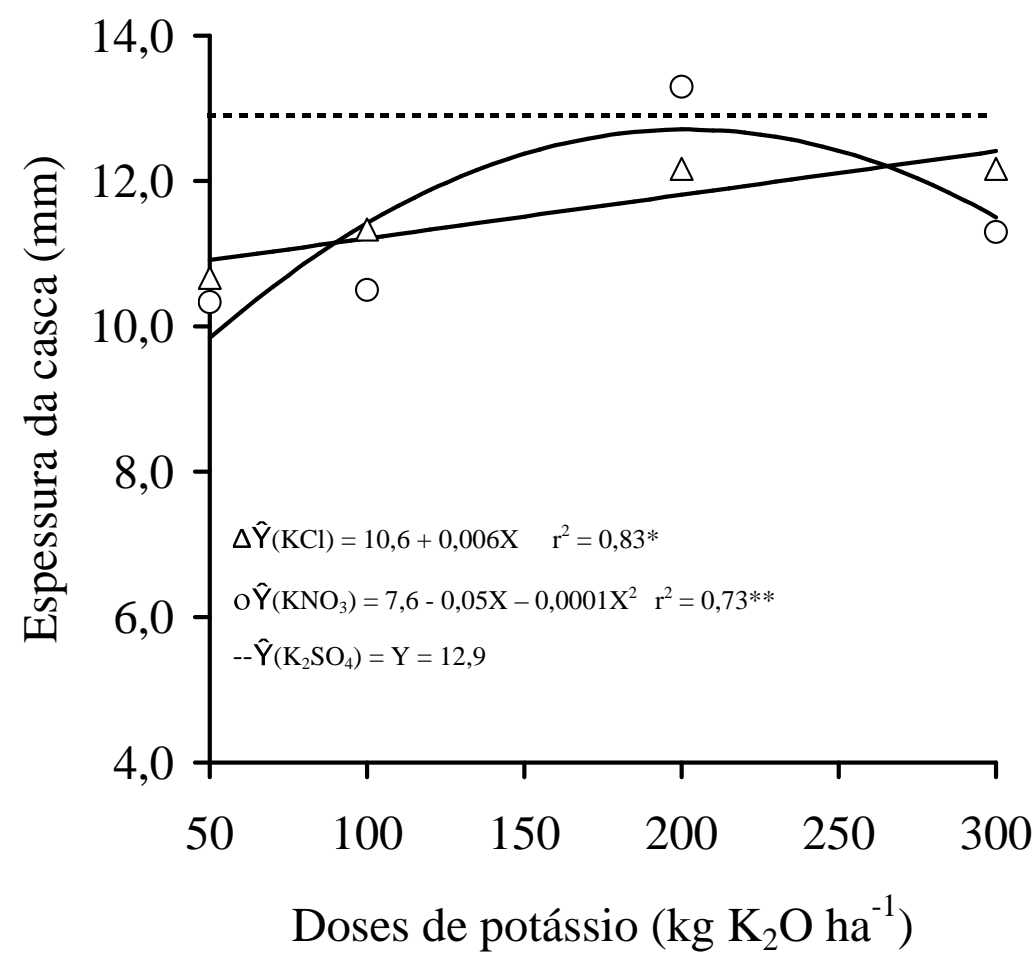

FIGURA 2 - Espessura da casca de frutos de melancia sem sementes, híbrido Shadow, em função das fontes e doses de potássio. Borborema - SP.

\section{CONCLUSÕES}

O teor de sólidos solúveis do fruto aumentou com a adubação potássica até a dose de $140 \mathrm{~kg} \mathrm{ha}^{-1} \mathrm{de}$ $\mathrm{K}_{2} \mathrm{O}$.

A relação SST/ATT dos frutos diminuiu linearmente com o aumento na dose de potássio.

As fontes de potássio não influenciaram o teor de sólidos solúveis dos frutos. potássica.

A acidez total não foi influenciada pela adubação

A espessura da casca aumentou de forma linear com as doses de potássio na fonte $\mathrm{KCl}$ e quadrática com $\mathrm{KNO}_{3}$.

\section{AGRADECIMENTOS}

À FAPESP, por auxílio financeiro concedido (processo 2000/01797-0); ao produtor rural Sr. Colombo, e a Alécio Schiavon Júnior, da Empresa Syngenta Seeds.

\section{REFERÊNCIAS BIBLIOGRÁFICAS}

AYDIN, S.; MORDOGAN, N.; YAGMUR, B.; GURPINAR, A.; KÜÇÜK, S. A. Effects of $\mathbf{K}_{2} \mathbf{S O}_{4}$ applications on fruit yield and some quality parameters in melon. Disponível em: < http://www. toprak.org.tr/isd/can_87.htm>. Acesso em: 22 nov. 2002.

CHITARrA, M. I.; CHITARRA, A. B. Pós-colheita de frutos e hortaliças: fisiologia e manuseio. Lavras: ESAL/FAEPE, 1990. 289 p.

CRUESS, W. V. Produtos industriais de frutos e hortaliças. São Paulo: Edgard Blücher, 1973. v. 1, 446 p.

DESWAL, I. S.; PATIL, V. K.; Effects of N, P and K on the fruit of water melon. Journal of Maharashtra Agricultural Universities, [S.1.], v. 9, n. 3, p. 308-309, 1984. 
EMPRESA BRASILEIRA DE PESQUISA AGROPECUÁRIA. Sistema brasileiro de classificação de solos. Brasília, 1999. 412 p.

EL-BEHEIDI, M. A.; EL-SHERBEINY, A. A.; ELSAWAH, M. H. Watermelon growth and yield as influenced by nutrition and irrigation methods in new reclaimed sandy soils. Egypt Journal Horticultural, [S.1.], v. 17, n. 1, p. 47-56, 1990.

FERNANDES, L. A. Manejo da fertirrigação nitrogenada e potássica na cultura do melão rendilhado (Cucumis melo reticulatus Naud). 2001. 64 f. Tese (Doutorado em Agronomia) - Faculdade de Ciências Agronômicas, Universidade Estadual Paulista, Botucatu, 2002.

FONTES, P. C. R.; SAMPAIO, R. A.; FINGER, F. L. Fruit size, mineral composition and quality of trickleirrigated tomatoes as affected by potassium rates. Pesquisa Agropecuária Brasileira, Brasília, v. 35, n. 1, p. 21-25, 2000.

GARCIA, L. F. Influência do espaçamento e da adubação nitrogenada sobre a produtividade da melancia no Baixo Parnaíba Piauiense. Teresina: EMBRAPA-CPAMN, 1998. 5 p. (Comunicado Técnico, n.79).

GEORGE, M. S.; LU, G.; ZHOU, W. Genotypic variation for potassium uptake and utilization efficiency in sweet potato (Ipomoea batatas L.). Field Crops Research, Amsterdam, v. 77, p. 7-15, 2002.

GOMES, F. P. Curso de estatística experimental. 12. ed. Piracicaba: Nobel, 1990. 466 p.

HARTZ, T. K.; GIANNINI, C.; MIYAO, G.; VALENCIA, J.; CAHN, M.; MULLEN, R.; BRITTAN, K. Soil cation balance affects tomato fruit color disorders. Acta Horticulturae, The Hague, n. 487, p. 49-55, 1999.

KANO, C. Extrações de nutrientes pelo meloeiro rendilhado cultivado em ambiente protegido com a adição de potássio e $\mathbf{C O}_{2}$ na água de irrigação. 2002. 102 f. Dissertação (Mestrado em Agronomia) - Escola Superior de Agricultura Luiz de Queiroz, Universidade de São Paulo, Piracicaba, 2002.

KINET, J. M.; PEET, M. M. Tomato. In: WIEN, H. C. The physiology of vegetable crops. New York: CAB Internacional, 1997. p. 207-258.
LOCASCIO, S. J.; OLSON, S. M.; GULL, D. D. Potassium source and rate and calcium rate effects on tomato yield and quality. HortScience, Alexandria, v. 25, n. 9, p. 1129,1990 .

MARR, C. W.; GAST, K. L. B. Reactions by consumers in a 'farmers' market to prices for seedless watermelon and ratings of eating quality. HortTechnology, Alexandria, v. 1, p. 105-106, 1991.

MENGEL, K.; KIRKBY, E. A. Principles of plant nutrition. 4. ed. Berne: International Potash Institute, 1987. $687 \mathrm{p}$.

MONTOYA, R. B.; SPINOIA, A. G.; GARCIA, P. S.; PAREDES, D. G. Demanda de potasio del tomate tipo sadette. Disponível em: $1<\mathrm{h}$ ttp://WwW.chapingd. $\mathrm{mx} /$ terra/contenido/20/4art 391-399.pdf. $>$. Acesso em: 18 dez. 2002.

MORALES, M. R.; SIMON, J. E. Seedless watermelon cultivar triale Southwestern Indiana. Disponível em: $<\mathrm{http} /$ www.hort.purdue.edu/hort/ext/veg/reports/INSIWm 00.html $>$. Acesso em: 18 nov. 2002.

NANNETTI, D. C. Nitrogênio e potássio aplicados via fertirrigação na produção, nutrição e póscolheita do pimentão. 2001. 184 f. Tese (Doutorado em Fitotecnia) - Universidade Federal de Lavras, Lavras, 2001.

PANIQUE, E.; KELLING, K. A.; SCHULTE, E. E.; HERO, D. E.; STEVENSON, W. R.; JAMES, R. V. Potassium rate and source effects on potato yield, quality, and disease interaction. American Potato Journal, Orono, v. 74, p. 379-398, 1997.

PAULA, M. B. de; CARVALHO, J. G. de; NOGUEIRA, F. D.; SILVA, C. R. de R. Exigências nutricionais do abacaxizeiro. Informe Agropecuário, Belo Horizonte, v. 11, n. 130, p. 27-31, 1985.

RAIJ, B. V.; CANTARELLA, H.; QUAGGIO, J. A.; FURLANI, A. M. C. Recomendações de adubação e calagem para o estado de São Paulo. Campinas: IAC, 1997. 285 p. (Boletim Técnico, 100).

REINA, L. del C. B. Conservação pós-colheita de tomate (Lycopersicon esculentum Mill) da cultivar gigante Kada submetido a choque a frio e armazenado com filme de PUC. 1990. 114 f. Dissertação (Mestrado em Fitotecnia) - Universidade Federal de Lavras, Lavras, 1990. 
REIS JÚNIOR, R. A. Produção, qualidade de tubérculos e teores de potássio no solo e no pecíolo de batateira em resposta à adubação potássica. 1995. 108 f. Dissertação (Mestrado em Fitotecnia) - Universidade Federal de Viçosa, Viçosa, 1995.

SOUZA, F. de F.; QUEIRÓZ, M. A. de; DIAS, R. de C. S. Melancia sem sementes: desenvolvimento e avaliação de híbridos triplóides experimentais de melancia. Biotecnologia Ciência e Desenvolvimento, Brasília, n. 9, p. 90-95, 1999.

SUNDSTROM, F. J.; CARTER, S. J. Influence of K and $\mathrm{Ca}$ on quality and yield of watermelon. Journal American Society for Horticultural Science, Alexandria, v. 108, n. 5, p. 879-881, 1983.
WESTERMANN, D. T.; JAMES, D. W.; TINDALL, T. A.; HURST, R. L. Nitrogen and potassium fertilization of potatoes: sugar starch. American Potato Journal, Orono, v. 71, p. 433-453, 1994.

WUZHONG, N. Yield and quality of fruits of solanaceous crops as affected by potassium fertilization. Better Crops, Atlanta, v. 13, n. 1, p. 6-8, 2002.

ZEHLER, E.; KREIP, H.; GETHING, P. A. Sulfato de potássio e cloreto de potássio: sua influência na produção e na qualidade das plantas cultivadas. Campinas: Fundação Cargill, 1986. $111 \mathrm{p}$. 